\title{
FEATURES OF APHIS FABAE DEVELOPMENT AND BIOCONTROL OF ITS NUMBER ON RED BEET CROPS
}

\section{V. Kyrychuk}

In Ukraine red beet occupies a leading position among vegetables both by cultivating area (9\%) accounting for 40-45 thousand ha, and by its consumption by population. The largest areas are concentrated Woodlands of Ukraine $9.9 \%$. The use of leading technologies ensures root yield of $70 \mathrm{t} / \mathrm{ha}$. The range of red beet varieties has been increasing in recent years, indicating the importance of these vegetables in the country $[1 ; 3]$.

Among the factors limiting the realization of potential productivity of red beet varieties, the leading role belongs to pests, including sucking phytophage, the most common and harmful of which is the beet leaf aphid - Aphis fabae Scop, (Homoptera, Pemphigidae) (Fig. 1), which is common in all areas of red beet cultivation, but most often makes harm in the zone of sufficient moisture of western part of the Right Bank of Ukraine.

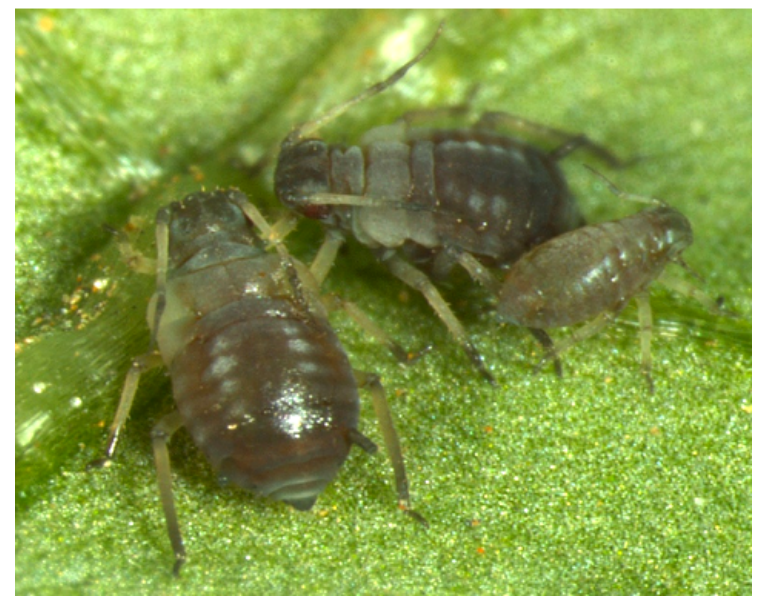

Figure 1. Beet leaf aphid (Aphis fabae Scop.)

(http://agroscience.com.ua/insecta/buryakova-lystko va-popelytsya/)

Beet leaf aphid is a digamous species. Makes damage to about 200 species of plants of sunflower, solanaceous, legume, gourd and other families. The harmfulness of aphids on red beet crops is that having settled on plants, it covers the underside of leaves, stems and buds (for drop-off) with dense colonies is a short period of time (Fig. 2). At this, leaves deform, twist in longitudinal direction, then fade, the stems stunt, and in case of mass reproduction of pests the stems and leaves dry up, resulting in weight and sugar content decrease, crops yield sharply reduces. The mass of roots commodity may be reduced to $30 \%$, sugar - by $1 \%$. In addition to the direct effects of aphids on the formation of crops and its quality, it is the main carrier of viral diseases - jaundice and leaves mosaic not only of beets and other crops.

Under favourable conditions, beet leaf aphid is able to quickly increase its population due to rapid biotic and parthenogenetic reproduction potential. On red beets the aphid reproduces up to the autumn, giving in this time $8-10$ or more generations of wingless and winged individuals that provide fast spreading over the crop. When temperature is $+23 \ldots+28^{\circ} \mathrm{C}$ and relative humidity is not less than $60-80 \%$ one generation develops in 10-14 days. So, first of all for timely and efficient conduct of complex plant protection measures against beet leaf aphid it is important to consider its biological characteristics and natural factors action regulating the number of phytophages.

Modern system of plant protection is the integration of different methods to reduce the number of economically harmful species to intangible levels. An integral part of integrated protection of red beet from sucking phytophages is chemical control method by spraying the crops, which is characterized by high technical performance, is the most cost-effective and mobile $[2 ; 5 ; 6]$.

However, today the introduction of environmentally safe plant protection techniques acquires special relevance to limit the number of pests, including the use of biological agents. Their use provides high quality (environmentally safe) products while maintaining biodiversity of agrocoenosis.

The objective of our research was to clarify the biological characteristics of beet leaf aphids on red beet crops, study the dynamics of its population and harmfulness, and improve the methods of regulation of phytophages population. 

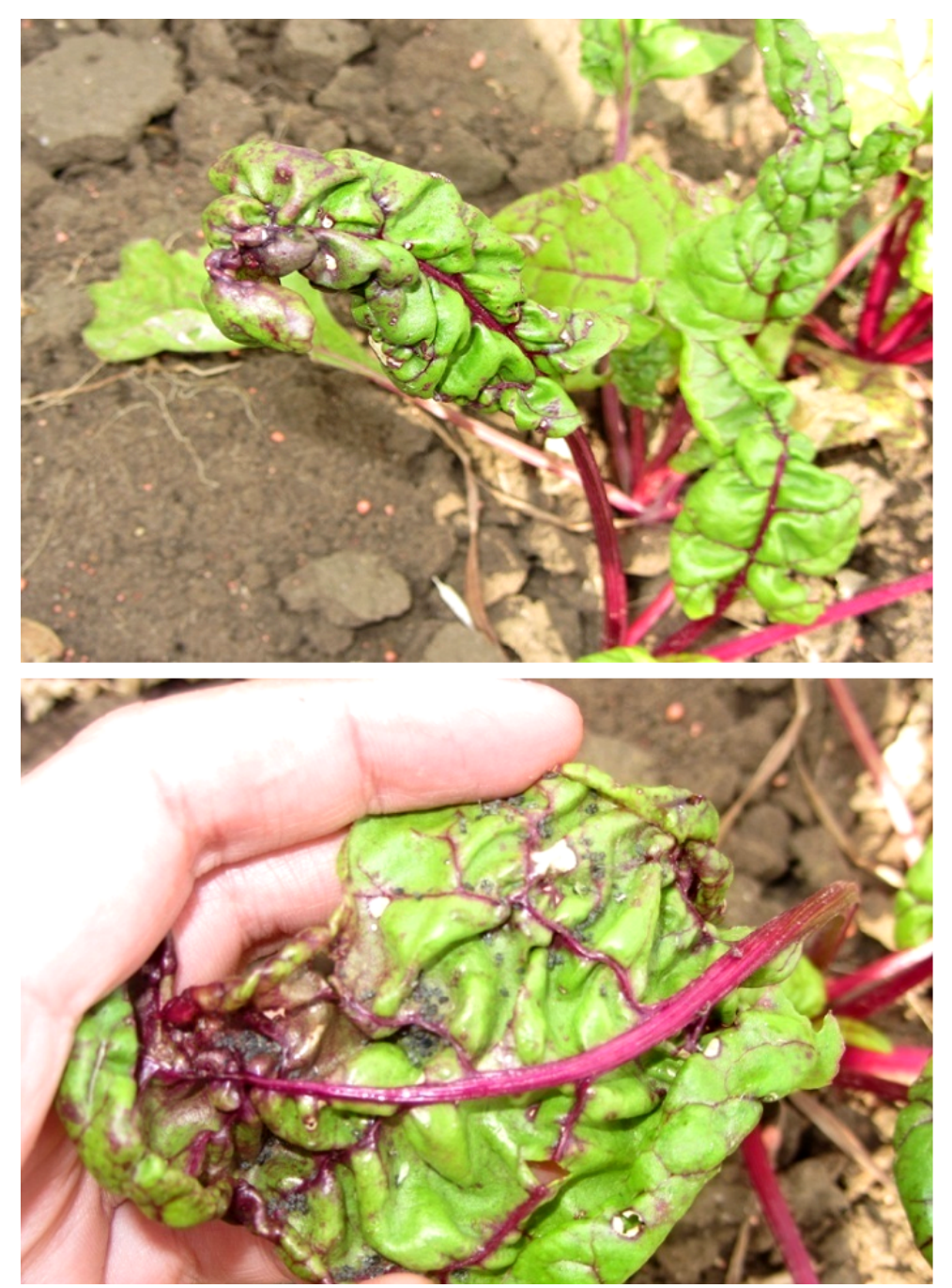

Figure 2. Damage of red beet by beet leaf aphid (Aphis fabae Scop) (AE “Kolos". Volyn region, 2014, original photo)

Materials and methods. Studies were conducted in 2013-2014 in the Woodlands of Ukraine (Volyn region, Kovel district, AE "Kolos") on the varieties of red beet of various groups of ripeness: Chervona kulia (early), Detroit (middle), Ataman (late).

For spraying the crops fungi-based biological agent Aktofit $0.2 \%$ emulsifiable concentrate (Aversectin C, 0.2\%) - 2.0 1/ha, bacterial agent - Bitoksybatsylin (BTU), liquid form (Bacillus thuringiensis var thuringiensis, endospores - titre $\left.1.0 \times 10^{9} \mathrm{CFU} / \mathrm{cm}^{3}\right)-51 /$ ha and insecticide Konfidor water-soluble concentrate (imidacloprid, $200 \mathrm{~g} / 1$ ) were applied with normal consumption of $0.21 /$ ha.

Calculations were conducted throughout the whole vegetation period every 10 days. The degree of colonization of plants with aphids was determined visually by a 9-point S. O. Trybel scale (Table 1) [7].
The area of research plot in the field experiment was $50 \mathrm{~m}^{2}$, repetition - quadruple, number of plants in the repetition -20 pcs. Plots location - single-row, randomized [4; 7].

Thus, it was found that in Ukrainian Woodlands beet leaf aphids develops on red beet in 8-9 generations. The most numerous colonies of phytophages were observed in the phase of inter-row leaves contact $-10,7-12,0 \%$. To a greater extent the pest inhabited late Ataman variety $-12.3 \%$ and late sowing crops - up to $17.7 \%$ of populated plants. It was established that agent Aktofit 0.2\% emulsifiable concentrate with the utilization rate of $21 /$ ha reduced the number of phytophages by $77.8 \%$, Bitoksybatsylin (BTU) $(5 \mathrm{l} / \mathrm{ha})$ - by $77.5 \%$, Konfidor water-soluble concentrate $(0.2 \mathrm{1} / \mathrm{ha})$ - by $78.7 \%$, that allowed to obtain crop yield growth to 5.7 t/ha. 